\title{
EXPERIMENTAL ANALYSIS OF THE INFLUENCE OF HEAT SINK GEOMETRIC PARAMETERS ON NATURAL CONVECTION
}

\author{
V. A. Silva, \\ B. C. S. Anselmo, \\ A. L. F. L. Silva, \\ and S. M. M. L. Silva \\ Universidade Federal de Itajubá - UNIFEI \\ Instituto de Engenharia Mecânica - IEM \\ Laboratório de Transferência de Calor - LabTC \\ Av. BPS, 1303, Bairro Pinheirinho \\ CEP 37500-903, Caixa Postal 50 \\ Itajubá, MG, Brasil \\ vilson@unifei.edu.br \\ Received: April 02, 2016 \\ Revised: May 25, 2016 \\ Accepted: June 15,2016
}

\section{ABSTRACT}

In this work, the steady state heat transfer by natural convection in heat sinks with rectangular fins positioned vertically and horizontally was studied. The heat transfer by radiation was also considered. Several analyses were performed to determine the optimal number and position of the sensors used to measure the temperature on the heat sinks horizontally and vertically positioned. These analyses confirmed an almost uniform temperature distribution in the heat sink. This uniformity allowed the use of thermocouples only in the center of the heat sink. Twelve heat sinks were designed to study how their geometric parameters such as height, spacing and thickness of the fins, influence the heat transfer by free convection. In addition, in this work, two correlations using the dimensionless parameters Nusselt and Rayleigh are proposed. These correlations were obtained by using the results from the 12 heat sinks vertically and horizontally positioned considering a temperature range between $20{ }^{\circ} \mathrm{C}$ and $100{ }^{\circ} \mathrm{C}$. Furthermore, studies were done to identify which of the 12 analyzed heat sinks managed to remove the greatest amount of heat in a given temperature range. The results were compared with those obtained from empirical correlations found in literature.

Keywords: heat sinks, free convection, rectangular fins, empirical correlation, heat transfer coefficient

\section{NOMENCLATURE}

\section{A MDF surface area, $\mathrm{m}^{2}$}

$\mathrm{A}_{\mathrm{ct}} \quad$ total area of convection, $\mathrm{m}^{2}$

b base plate thickness, $\mathrm{mm}$

$\mathrm{b}_{\mathrm{p}} \quad$ thickness of MDF, mm

$\mathrm{H}$ height of the heat sink, mm

$\overline{\mathrm{h}}$ average heat dissipation coefficient, $\mathrm{W} / \mathrm{m}^{2} \mathrm{~K}$

I electric current, A

$\mathrm{L} \quad$ length of the heat sink, $\mathrm{mm}$

l (=L/2), half of the fin length, $\mathrm{mm}$

$\mathrm{K}_{\mathrm{f}} \quad$ fluid thermal conductivity, W/(m.K)

$\mathrm{K}_{\text {iso }}$ thermal conductivity of MDF, W/(m.K)

MDF Medium-Density Fiberboard

$\mathrm{n} \quad$ number of fins

P Power provided to the heater, $\mathrm{W}$

$\mathrm{Nu} \quad$ Nusselt number

$\mathrm{q}_{\text {iso }} \quad$ heat rate lost by conduction, Eq. (8), W

$\mathrm{q}_{\mathrm{pl}} \quad$ heat rate, Eq. (6), W

$\mathrm{q}_{\mathrm{rad}}$ heat rate lost by radiation, Eq. (9), W

$\mathrm{Ra}$ Rayleigh number

$\mathrm{R}_{\mathrm{aq}} \quad$ heater resistance, $\Omega$

$\mathrm{R}_{\text {fio }} \quad$ resistance of the wire heater, $\Omega$

$\mathrm{S}$ fin spacing, $\mathrm{mm}$

$\mathrm{t}$ thickness of the fin, $\mathrm{mm}$

$\mathrm{T}_{1} \quad$ environmental temperature, ${ }^{\circ} \mathrm{C}$

$\mathrm{T}_{2}$ temperature below on the MDF, ${ }^{\circ} \mathrm{C}$

$\mathrm{T}_{3} \quad$ heater temperature, ${ }^{\circ} \mathrm{C}$

$\mathrm{T}_{\text {conv }}$ average temperature on top and basis of the fins, ${ }^{\circ} \mathrm{C}$

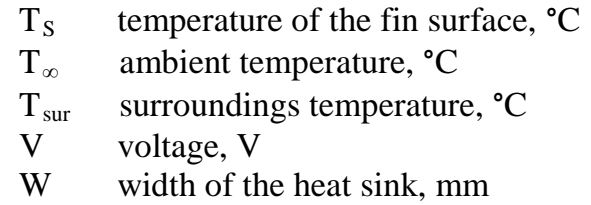

\section{Greek symbols}

$\varepsilon \quad$ emissivity of aluminum 6063-T5

$\Delta$ difference

\section{INTRODUCTION}

A fin is an extended surface from an area where a high heat transfer with the environment is desired. A set of fins is called heat sink. The larger the area of a heat sink, the higher the heat transfer rate. Heat sinks are used in several pieces of equipment that may generate heat and have little space to dissipate heat as motors, transformers, heat exchangers and microprocessors. Heat sinks have been widely studied in order to make better heat transfer rate and in smaller areas without losing their performance.

Natural convection is usually used because it presents high reliability and lower cost and does not use energy. The choice of a heat sink considers the rate of heat dissipated. This rate can be calculated by knowing the average heat transfer coefficient by convection, $\bar{h}$, which is a property that depends on the fluid flow conditions and the geometry of the 
surface. The values of $\bar{h}$ can be found by resorting to experiments, numerical solutions and empirical correlations.

Following the idea developed by Silva et al. (2014), where several heat sinks were tested, two empirical correlations were proposed. Hence, in this work, these new correlations were improved by using more results and the software LABfit. This software LABfit may be used to obtain an equation that can be used to obtain values for the Nusselt Number used to calculate the heat transfer coefficient by convection $\bar{h}$. Furthermore, an analysis concerning the positions of the heat sink basis was done pointing out that the vertical position is better than the horizontal to remove heat, as seen in Mehrtash and Tari (2013) in their numerical investigation.

Mehrtash and Tari (2013) studied the heat sinks in different positions by varying their angles from horizontal to vertical and downwards. This study focused on numerical simulations and on investigation about Nusselt and Rayleigh Numbers. The purpose was to propose correlations for Rayleigh Number by using the numerical simulations for vertical heat sinks and different angles by using the cosine as an adjustment parameter.

Using heat sinks vertically positioned, Kim et al. (2013) studied the characteristics of the outflow and the heat transfer with the help of the software FLUENT ${ }^{\circledR}$. The authors concluded that optimization of the space between fins do not depend on the height, however, it depends on the length, on the difference between the temperature of the heat sink and the environment, and on the fluid properties. The correlation proposed by Kim et al. (2013) was considered more accurate and with a wider range than some correlations proposed previously.

The material of the fins must display high thermal conductivity, and in the present work, aluminum 6063-T5 was used. The material of the fin has great influence on the heat transfer rate once it directly affects the temperature distribution along the extended surface. The optimal configuration would occur if the thermal conductivity of the fin was infinite, thus the temperature along the fin would be the same as the base, providing a maximum rate of heat transfer.

In this study, the average heat transfer coefficient by convection of twelve heat sinks was determined for vertical and horizontal positions. These values were compared with the empirical correlation obtained by Harahap and Rudianto (2005) for horizontal and by Harahap and Lesmana (2006) for vertical.

\section{THEORETICAL BASIS}

\section{Calculation of the Average Heat Transfer Coefficient by Convection}

Heat transfer by free convection occurs whenever there is a temperature difference between a body and a fluid. This difference in temperature causes a change in the density of the fluid near the surface. The difference in density means that there is a downward flow of the heavier fluid and an upward flow of the lighter one. The convective heat transfer that occurs due to the difference between the densities of the fluid is called natural convection.

The theoretical coefficients obtained in this work were based on empirical correlations proposed by Harahap and Rudianto (2005) and Harahap and Lesmana (2006). The correlations are obtained from a series of tests for assessment of experimental data. The accuracy with which the heat transfer coefficient can be calculated depends on the correlation used.

Natural convection is characterized by the dimensionless numbers of Nusselt, Grasshof, Prandtl and Rayleigh. Nusselt number represents the ratio between the heat transfer by convection and by conduction. Grasshof number indicates a ratio of the buoyant forces and the viscous forces, and Prandtl number represents the ratio between the momentum and thermal diffusivities.

Empirical correlation of Harahap and Rudianto (2005)

Harahap and Rudianto (2005) proposed a correlation to describe natural convection in horizontal finned rectangular heat sinks. The correlation proposed by these authors uses Rayleigh and Nusselt numbers calculated in relation to the size of $l$, where $l=L / 2$. Thus, Nusselt number is calculated from the equation below:

$$
\begin{aligned}
& \mathrm{Nu}=0.203 \cdot\left[\operatorname{Ra}\left(\frac{\mathrm{nS}}{\mathrm{H}}\right)\right]^{0.393} \cdot\left(\frac{\mathrm{S}}{\mathrm{l}}\right)^{0.470} \\
& \cdot\left(\frac{\mathrm{H}}{\mathrm{l}}\right)^{0.870} \cdot\left(\frac{\mathrm{L}}{\mathrm{W}}\right)^{0.620}
\end{aligned}
$$

and the average value of the heat transfer coefficient by convection is given by:

$$
\overline{\mathrm{h}}=\frac{\mathrm{Nu} \cdot \mathrm{k}_{\mathrm{f}}}{\mathrm{l}}
$$

The correlation obtained by Harahap and Rudianto (2005) is indicated for a range of values between $3.0 \times 10^{3} \leq \operatorname{Ral}_{n}(S / L) \leq 3.0 \times 10^{5}$. The use of this correlation for values outside this range increases the error of the values obtained for $\bar{h}$.

Empirical correlation of Harahap and Lesmana (2006)

The heat transfer data for vertical surfaces were experimentally correlated by Harahap and Lesmana (2006). The correlation proposed by these authors uses Rayleigh number and Nusselt in relation to size 
of $L$.

$$
\mathrm{Nu}=3.350 \cdot(\mathrm{Ra})^{0.153} \cdot\left(\frac{\mathrm{L}}{\mathrm{H}}\right)^{0.121} \cdot\left(\frac{\mathrm{S}}{\mathrm{H}}\right)^{0.605}
$$

and the average value of the heat transfer coefficient by convection is given by:

$$
\overline{\mathrm{h}}=\frac{\mathrm{Nu} \cdot \mathrm{k}_{\mathrm{f}}}{\mathrm{L}}
$$

The correlation obtained by Harahap and Lesmana (2006) is indicated for a range of values between $20 \times 10^{4} \leq R a_{L} \leq 5 \times 10^{5}$.

\section{Obtaining the experimental $\bar{h}$}

To obtain the experimental values of $\bar{h}$, Newton's cooling law was used, given as:

$$
\overline{\mathrm{h}}=\frac{\mathrm{q}_{\mathrm{pl}}}{\mathrm{A}_{\mathrm{Ct}}\left(\mathrm{T}_{\mathrm{S}}-\mathrm{T}_{\infty}\right)}
$$

where $A_{c t}$ is the total surface area of the heat sink in contact with the fluid, $q_{p l}$ is the difference between the heat transfer rate provided by the heater and lost by conduction through the insulator $\left(q_{\text {iso }}\right)$ and lost by radiation through the heat $\operatorname{sink}\left(q_{\text {rad }}\right)$.

$$
\mathrm{q}_{\mathrm{pl}}=\mathrm{P}-\mathrm{q}_{\mathrm{iso}}-\mathrm{q}_{\text {rad }}
$$

For the calculation of the heater power $\mathrm{P}$ (Eq. 6 ), the power dissipated by the heater wire which connects to the power supply should be disregarded, therefore the calculation $\mathrm{P}$ is done by equation:

$$
\mathrm{P}=\frac{\left(\mathrm{V}-\mathrm{R}_{\mathrm{fio}} \mathrm{I}\right)^{2}}{\mathrm{R}_{\mathrm{aq}}}
$$

The calculation of $q_{\text {iso }}$ and $q_{\text {rad }}$ can be done with Fourier's and Stefan-Boltzmann's Laws, as shown below.

$$
\begin{gathered}
\mathrm{q}_{\mathrm{iso}}=\mathrm{k} \cdot \mathrm{A} \frac{\Delta \mathrm{T}_{\mathrm{iso}}}{\mathrm{L}}=\mathrm{k}_{\mathrm{iso}} \cdot \mathrm{A} \frac{\left(\mathrm{T}_{3}-\mathrm{T}_{2}\right)}{\mathrm{b}_{\mathrm{p}}} \\
\mathrm{q}_{\mathrm{rad}}=\varepsilon \cdot \sigma \cdot \mathrm{A}_{\mathrm{ct}} \cdot\left(\mathrm{T}_{\mathrm{S}}^{4}-\mathrm{T}_{\mathrm{viz}}^{4}\right) \\
=\varepsilon \cdot \sigma \cdot \mathrm{A}_{\mathrm{ct}} \cdot\left(\mathrm{T}_{\mathrm{conv}}^{4}-\mathrm{T}_{1}^{4}\right)
\end{gathered}
$$

Figure 1 shows an explanation of heat distribution from the heater to the heat sink and to the MDF insulation.

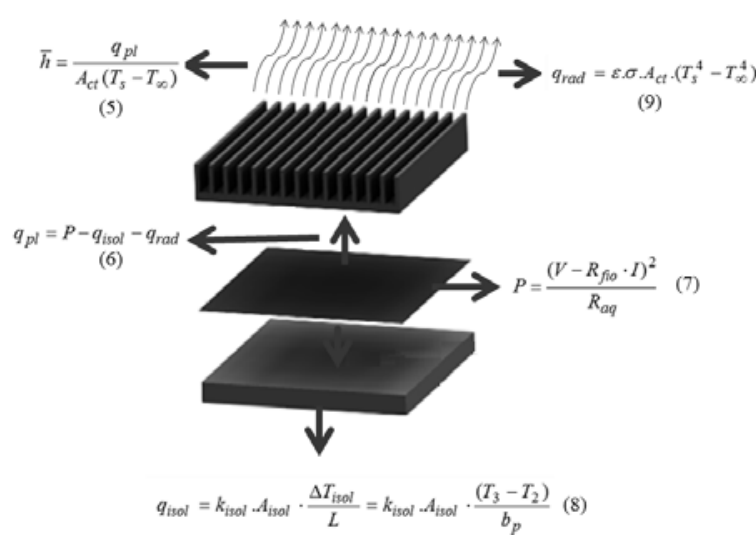

Figure 1. Heat distribution illustration in the experimental set.

\section{EXPERIMENTAL ASSEMBLY}

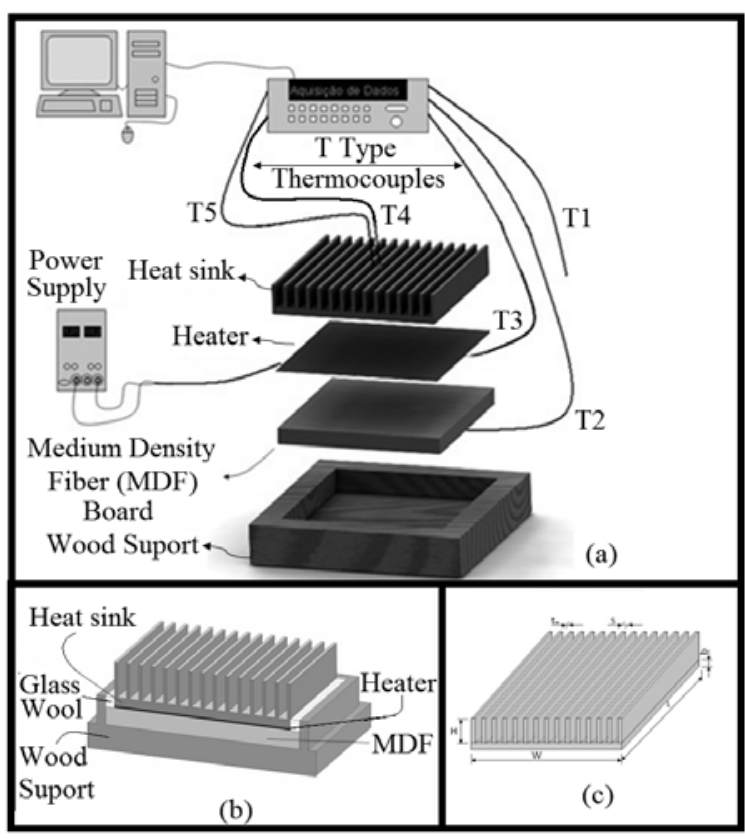

Figure 2. (a) Arrangement of test bench, (b) details of the heatsink and (c) heatsink geometric parameters.

The experimental apparatus illustrated in Fig. 2a was developed to conduct the tests. The heat sink is assembled on a resistive heater and both placed on a wood support as shown in Fig. 2b. This assembly reduces heat loss through the lower surface of the heater and does not restrict the air flow around the peripheral fins. The sidewalls of the support were isolated with glass wool to prevent heat exchange between the support and the heat sink. Additionally, a medium density fiberboard was used to isolate the bottom of the heater to keep it from bending and to keep it in contact with the base of the heatsink.

The heat sinks were machined from a single 6063-T5 aluminum bar to ensure that the physical properties. Figure 2c and Table 1 show the geometric parameters values that made each heat sink different 
and unique.

Table 1. Dimensions of the Heat sinks.

\begin{tabular}{|c|c|c|c|c|c|c|c|c|}
\cline { 2 - 10 } \multicolumn{1}{c|}{} & $\mathbf{S}[\mathbf{m m}]$ & $\mathbf{t}[\mathbf{m m}]$ & $\mathbf{H}[\mathbf{m m}]$ & $\mathbf{L}[\mathbf{m m}]$ & $\mathbf{W}[\mathbf{m m}]$ & $\mathbf{b}[\mathbf{m m}]$ & $\mathbf{n}$ & $\mathbf{A}_{\mathbf{c t}}\left[\mathbf{m}^{2}\right]$ \\
\hline Heat sink & $\begin{array}{c}\text { Fin } \\
\text { spacing }\end{array}$ & Thickness & Height & Lenght & Width & $\begin{array}{c}\text { Base Plate } \\
\text { Thickness }\end{array}$ & $\begin{array}{c}\text { Number of } \\
\text { Fins }\end{array}$ & $\begin{array}{c}\text { Total Area } \\
\text { of } \\
\text { Conrection }\end{array}$ \\
\hline H1 & 14.35 & 2.00 & 14.00 & 100.00 & 100.10 & 4.00 & 7 & 0.0300 \\
\hline H2 & 5.55 & 2.00 & 14.00 & 100.00 & 100.15 & 4.00 & 14 & 0.0500 \\
\hline H3 & 14.35 & 2.00 & 20.00 & 100.00 & 100.10 & 4.00 & 7 & 0.0386 \\
\hline H4 & 5.55 & 2.00 & 20.00 & 100.00 & 100.15 & 4.00 & 14 & 0.0671 \\
\hline H5 & 14.35 & 2.00 & 7.00 & 100.00 & 100.10 & 4.00 & 7 & 0.0200 \\
\hline H6 & 5.55 & 2.00 & 7.00 & 100.00 & 100.15 & 4.00 & 14 & 0.0300 \\
\hline H7 & 12.00 & 4.00 & 7.00 & 100.00 & 100.00 & 4.00 & 7 & 0.0201 \\
\hline H8 & 3.15 & 2.00 & 7.00 & 100.00 & 99.85 & 4.00 & 20 & 0.0385 \\
\hline H9 & 3.15 & 2.00 & 20.00 & 100.00 & 99.85 & 4.00 & 20 & 0.0915 \\
\hline H10 & 12.00 & 4.00 & 20.00 & 100.00 & 99.85 & 4.00 & 7 & 0.0391 \\
\hline H11 & 3.15 & 2.00 & 14.00 & 100.00 & 99.85 & 4.00 & 20 & 0.0671 \\
\hline H12 & 12.00 & 4.00 & 14.00 & 100.00 & 99.85 & 4.00 & 7 & 0.0304 \\
\hline
\end{tabular}

The heater used consists of a very thin electrical resistance which can withstand temperatures up to $150^{\circ} \mathrm{C}$, already bearing a type $\mathrm{T}$ thermocouple inside. This thermocouple is more reliable once it reduces the contact resistance between the heater and the sample and the heater and the MDF isolation. This resistive heater was manufactured by Professor Saulo Güths at Laboratório de Meios Porosos e Propriedades Termofisicas (LMPT) in the Department of Mechanical Engineering at UFSC. This heater was connected to a power source Instrutemp ST-II-305D DC with digital current and voltage display. The twelve heat sinks with different geometrical parameters and the same base were machined from a homogeneous 6063-T5 aluminum bar at the Machining Laboratory at UNIFEI. This aluminum was chosen due to its wide use in heatsinks and the fact of presenting high thermal conductivity and low density, which are essential characteristics for heat sinks. Another important factor was its affinity with the capacitive discharge welding, a process used to attach the thermocouples directly to the heat sinks.

Five type $\mathrm{T}$ thermocouples were used in the assembly. The capacitive discharge welding (Lima et al., 2002) was used because it reduces the contact resistance between the thermocouple and the heat sink. The thermocouples were connected to a data acquisition system, Agilent 34980A, controlled by a computer that filed the temperatures data. The arrangement of the heat sink positioned horizontally and vertically is shown in Fig. $3 a$ and $3 b$, respectively.

The thermocouple positions were determined by an experimental test where some thermocouples attached to specific parts of the heat sinks were used (Figures 4a1-a4). This procedure was used to analyze the heat distribution and the best place to put the thermocouples. The results of these tests can be seen in Figures 4b1 and b2 which showed the behavior of the temperature of the heat sinks in vertical and horizontal positions, respectively. It may be seen that there was practically no change in temperature, so only one thermocouple in the center of the heat sink was used.
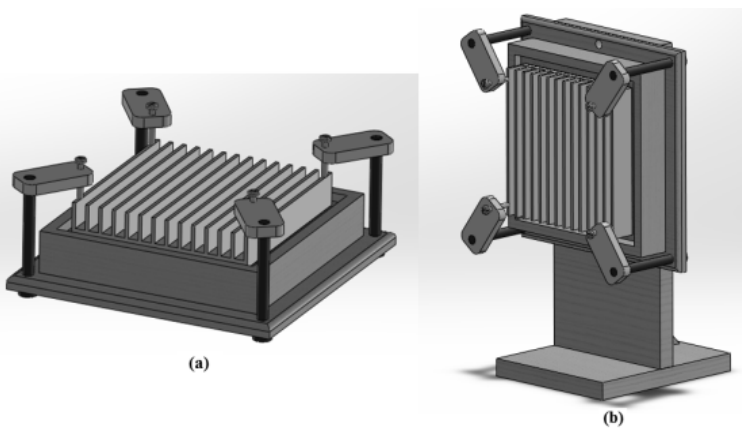

Figure 3. (a) Horizontal and (b) vertical heat sink assemblies.

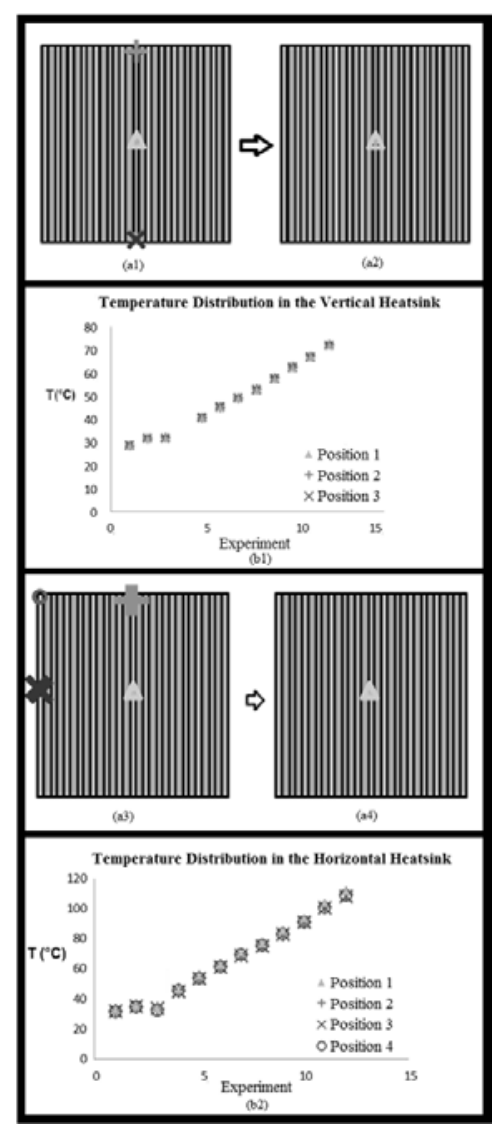

Figure 4. (a1) and (a3) positions of the thermocouples during the distribution test; (a2) and (a4) positions of the thermocouples in the other tests; and (b1) and (b2) refer to temperature distribution of each thermocouple.

\section{RESULTS AND DISCUSSION}

With the experimental temperatures and constants (like voltage, current, thermal conductivity, the dimensions of the aluminum heat sinks and MDF boards), the average heat transfer coefficient by convection and the Nusselt number can be calculated. After nearly 120 minutes, the experimental bench was under steady state and the data started to be 
collected. 500 pieces of data were collected; however, the 50 last values were used to obtain the average temperature of each thermocouple and this procedure was done 5 times to ensure repeatability. As an example, Heat sink 8 was warmed for 145 minutes and it can be seen that the difference between the temperatures registered between 120 and 140 minutes was lower than 1\% (Fig. 5). Therefore, the steady state is guaranteed when the temperature variation of a thermocouple in 20 minutes was less than $1 \%$.

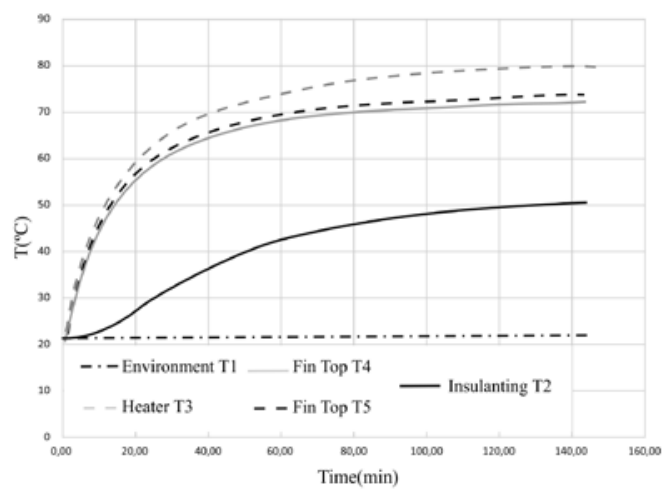

Figure 5. Temperature variation in time for the five thermocouples of Fig. 1.

To demonstrate the behavior of $\bar{h}$ in two heat sinks, the experimental results for $\bar{h}$ were compared to the correlations of Harahap and Rudianto (2005) and Harahap and Lesmana (2006) in Fig. 6. And in addition, comparisons between the horizontal and vertical positions were carried out. It may be seen that, in some cases, the curves present satisfactory results and other cases they present a small difference, however the same behavior. It may be seen that the vertical heat sinks presented a higher $\bar{h}$ than the horizontal ones, which shows they dissipate more heat than the horizontal heat sinks.

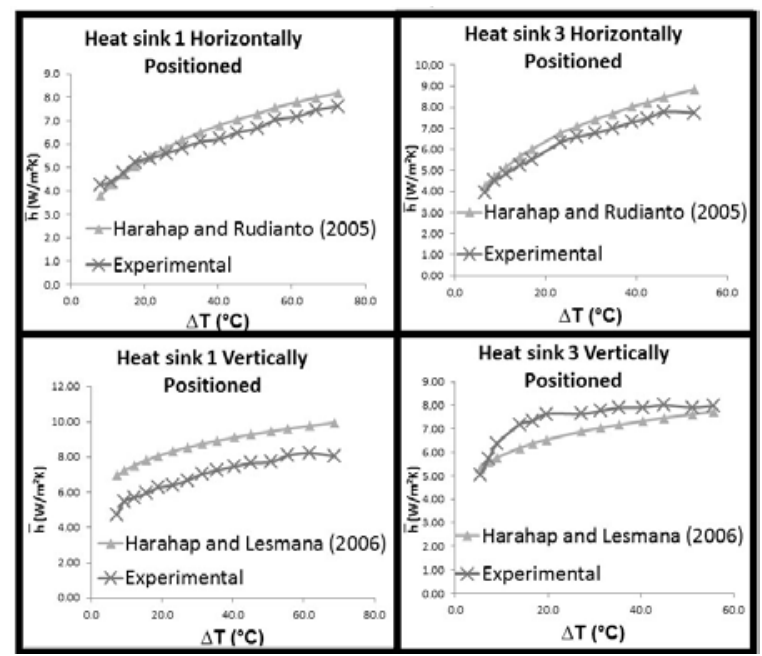

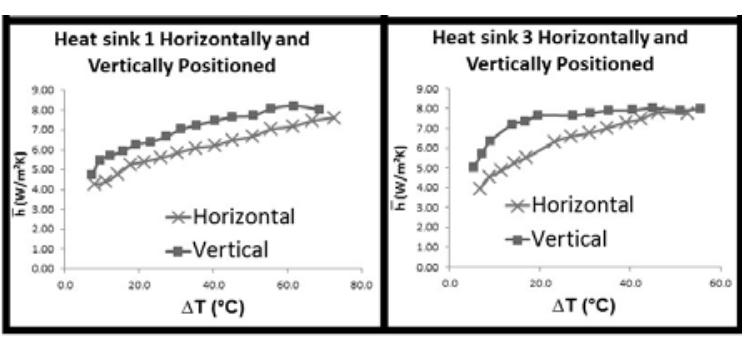

Figure 6. Heat transfer coefficient variation in temperature for Heat sinks 1 and 3.

Figure 7 shows the relation between the power provided and the temperature that has been achieved by the heatsink. Through this relation the heat sinks can be classified and identified according to their capacity of losing heat as in Table 2.

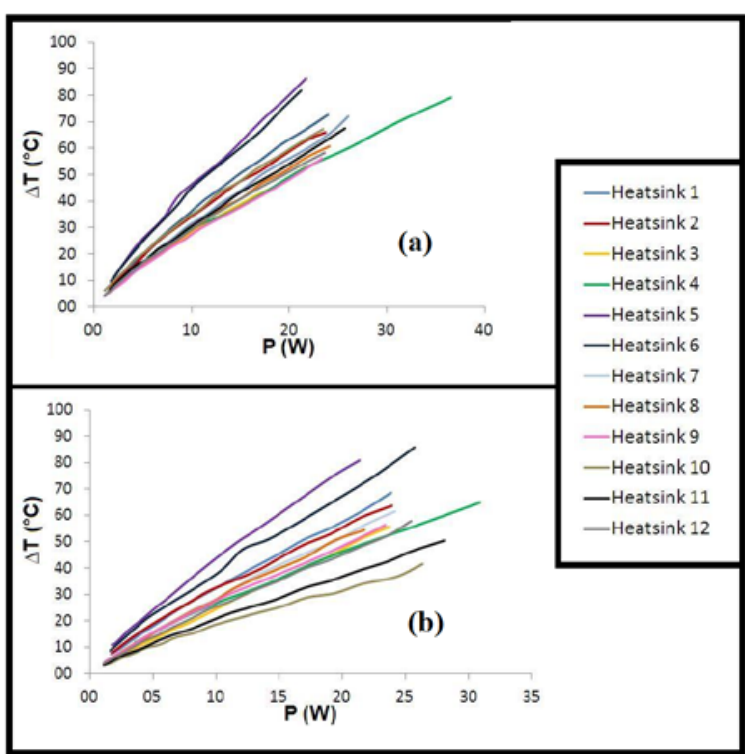

Figure 7. Temperature variation in relation to the power supply a) for horizontal and b) for vertical heat sinks.

Table 2. Heat sink classification.

\begin{tabular}{|c|c|c|c|c|c|c|}
\cline { 2 - 7 } \multicolumn{1}{c|}{} & Position & \multicolumn{2}{c|}{ For P=10W } & Position & \multicolumn{2}{c|}{ For P=10W } \\
\hline Classification & Horizontal & {$\left[\mathbf{W} / \mathbf{m}^{2} \cdot \mathbf{K}\right]$} & {$\left[{ }^{\circ} \mathbf{C}\right]$} & Vertical & {$\left[\mathbf{W} / \mathbf{m}^{2} \cdot \mathbf{K}\right]$} & {$\left[{ }^{\circ} \mathbf{C}\right]$} \\
\hline $1^{\text {st }}$ & H 3 & 6.58 & 26.86 & H10 & 10.79 & 18.16 \\
\hline $2^{\text {nd }}$ & H9 & 1.93 & 29.20 & H11 & 4.89 & 19.61 \\
\hline $3^{\text {rd }}$ & H11 & 2.48 & 29.35 & H12 & 9.16 & 24.66 \\
\hline $4^{\text {th }}$ & H4 & 2.84 & 30.79 & H3 & 7.64 & 27.28 \\
\hline $5^{\text {th }}$ & H7 & 11.67 & 30.86 & H8 & 6.29 & 27.39 \\
\hline $6^{\text {th }}$ & H12 & 7.89 & 32.06 & H7 & 13.19 & 27.66 \\
\hline $7^{\text {th }}$ & H8 & 6.19 & 32.41 & H4 & 3.35 & 28.12 \\
\hline $8^{\text {th }}$ & H2 & 3.36 & 33.32 & H1 & 7.03 & 31.42 \\
\hline $9^{\text {th }}$ & H10 & 4.28 & 33.97 & H2 & 3.56 & 31.80 \\
\hline $10^{\text {th }}$ & H1 & 6.09 & 35.21 & H9 & 1.67 & 32.12 \\
\hline $11^{\text {th }}$ & H6 & 4.04 & 45.20 & H6 & 5.28 & 37.72 \\
\hline $12^{\text {th }}$ & H5 & 6.74 & 46.33 & H5 & 7.29 & 49.43 \\
\hline
\end{tabular}

To conclude this study, two correlations were proposed for Nusselt number for vertically and 
horizontally positioned heat sinks. To develop these new correlations, all data collected during the experiments were used. A worksheet was accomplished with the values for Nusselt and Rayleigh numbers and the all geometric parameters of the 12 heat sinks used. For this, the software LAB Fit, developed by Wilton and Cleide Pereira da Silva from Universidade Federal de Campina Grande (http://zeus.df.ufcg.edu.br/labfit/index_p.htm) was used. Values of Nusselt and Rayleigh as well as independent dimensionless variables: $R a, S / L, H / L$ were provided to LAB Fit. The software furnished the form that the equation of correlation must have. This work selected the following equation, that uses $L$ as the characteristic length of the heat sink:

$$
\mathrm{Nu}=\mathrm{A} \cdot \mathrm{Ra}^{\mathrm{B}} \cdot(\mathrm{S} / \mathrm{L})^{\mathrm{C}} \cdot(\mathrm{H} / \mathrm{L})^{\mathrm{D}} \cdot(\mathrm{t} / \mathrm{L})^{\mathrm{E}} \cdot \mathrm{n}^{\mathrm{F}}
$$

where the terms $A, B, C, D, E$, and $F$ are the coefficients given by the $\mathrm{LAB}$ fit after the curve fit.

The curve fit for both cases presented good results because their quadratic average was higher than $80 \%$. The correlations are as follow:

Horizontally positioned heat sinks:

$$
\begin{aligned}
& \mathrm{Nu}=0.086 \cdot \mathrm{Ra}^{0.266} \cdot(\mathrm{S} / \mathrm{L})^{-0.567} . \\
& \cdot(\mathrm{H} / \mathrm{L})^{-0.0169} \cdot(\mathrm{t} / \mathrm{L})^{-1.068} \cdot \mathrm{n}^{-1.580}
\end{aligned}
$$

with:

$$
4.6 \times 10^{4}<\text { Ra }<5.8 \times 10^{5}
$$

Vertically positioned heat sinks:

$$
\begin{gathered}
\mathrm{Nu}=0.042 \cdot \mathrm{Ra}^{0.229} \cdot(\mathrm{S} / \mathrm{L})^{0.455} . \\
(\mathrm{H} / \mathrm{L})^{-0.0112} \cdot(\mathrm{t} / \mathrm{L})^{-1.082} \cdot \mathrm{n}^{-0.119}
\end{gathered}
$$

with: $\quad 2.9 \times 10^{5}<R a<4.6 \times 10^{6}$

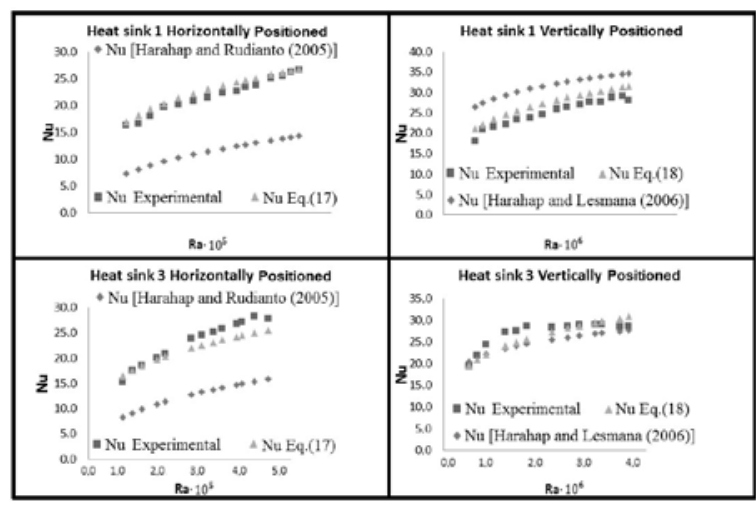

Figure 8. Application of the new correlations from Eq. (11) and Eq. (12).

Figure 8 shows the comparisons between the results of Nusselt number obtained from Eqs. (11 and
12) for Heat sinks 1 and 3 and the experimental and literature results. It can be seen that Eqs. (11) and (12) presented good results when compared with experimental Nusselt number. These same behaviors were presented for all other heat sinks.

\section{CONCLUSIONS}

In this work a detailed study of the influence of the geometric parameters such as height, space, thickness and number of fins for heat sinks subject to natural convection was presented. For this, twelve 6063-T5 aluminum heat sinks with rectangular fins were designed and machined.

The results obtained for $\bar{h}$ showed higher values of $\bar{h}$ were obtained for heat sinks with the base in vertical orientation. This happens due to the fact that in this position the upward flow of air which has been warmed on the underside of the heat sink helps in cooling the heat sink from its base to the tip of the fin. This explains the reason of the heat sinks that are vertically oriented are more effective the greater the space between their fins. The greater the space between them the better will be for air flow. In the heat sinks horizontally positioned this phenomena of air circulation due to its heating also occurs, but this stream acts with more intensity on the tip of the fins. This explains the reasons of heat sinks, horizontally positioned, that have larger fins are more effective.

The most important factor in the performance of the heat sinks was the number of fins, hence the distance between them, and their heights. When the heat sink was positioned with the base on the horizontal and the vertical fins they have that the greater the number of fins and the greater height better will be the performance of the heat sink. For vertically positioned based heat sinks and fins, the greater the space of the fins and their height, the better will be the performance of the heat sink.

Finally another contribution of this work was to propose two empirical correlations to calculate the Nusselt number of these heat sinks. One for the heat sink with the base on the horizontal and vertical fins and another for the heat sink with the base and the fins on the vertical position. These correlations were obtained for the Nusselt number which is the dependent variable and it is written as a function of five independent variables which are: the Rayleigh number, the height, the space, the thickness and the number of fins. As these proposed correlations used dimensionless parameters, they can be used for the evaluation of other heat sinks with different geometric parameters, but you must use the heat sink/fin length as the greatness feature of the heat sink studied.

\section{ACKNOWLEDGEMENTS}

The authors would like to thank CNPq, FAPEMIG and CAPES for their financial support. 


\section{REFERENCES}

Dogan, M., and Sivrioglu, M., 2009, Experimental Investigation of Mixed Convection Heat Transfer from Longitudinal Fins in a Horizontal Rectangular Channel: in Natural Convection Dominated Flow Regimes, Energy Conversion and Management, Vol. 50, pp. 2513- 2521.

Harahap, F., and Rudianto, E., 2005, Measurements of Steady-State Heat Dissipation from Miniaturized Horizontally Based Straight Rectangular Fin Arrays, Heat and Mass Transfer, Vol.41, pp. 280-288.

Harahap, F., and Lesmana, H., 2006, Measurements of Heat Dissipation From Miniaturized Vertical Rectangular Fin Arrays Under Dominant Natural Convection Conditions, Heat and Mass Transfer, Vol.42, pp. 1025-1036.

Kim, T. H., Kim, D. K., and Do, K. H., 2013, Correlation for the Fin Nusselt Number of Natural Convective Heat Sinks with Vertically Oriented Plate-Fins, Heat and Mass Transfer, Vol. 49, pp. 413425.

Lima e Silva, S. M. M., Borges, V. L., Vilarinho, L. O., Scotti, A., and Guimarães, G., 2002, Desenvolvimento de uma Técnica Experimental para a Determinação do Fluxo de Calor em um Processo de Soldagem TIG, in: 9th Brazilian Congress of Thermal Sciences and Engineering - ENCIT 2002, Caxambu, Minas Gerais, Brasil. (in Portuguese)

Mehrtash, M., and Tari, I., 2013, A Correlation for Natural Convection Heat from Inclined Platefinned Heat Sinks, Applied Thermal Engineering, Vol. 51, pp. 1067-1075

Silva, V. A., Lima e Silva, A. L. F., and Lima e Silva, S. M. M., 2014, Analysis of Heat Transfer Coefficients by Natural Convection in Horizontal and Vertical Heatsinks, in: 15th Brazilian Congress of Thermal Sciences and Engineering - ENCIT 2014, Belém, Pará, Brasil. 